\title{
ENTRY INTO VOCATIONAL REHABILITATION PROGRAM FOLLOWING WORK-RELATED HAND INJURY: POTENTIAL CANDIDATES
}

\author{
YUEH-HSIA CHEN ${ }^{1}$, CHUNG-YIN HSU ${ }^{2}$, SHWU-HUEI LIEN ${ }^{1}$, SHU-JUNG YU ${ }^{1}$, JEN-MU CHANG ${ }^{1}$, \\ SHANQ-WEN SU ${ }^{1}$, and YUAN-HUNG CHAO ${ }^{3}$ \\ ${ }^{1}$ Chang Gung Memorial Hospital, Taoyuan County, Taiwan \\ Rehabilitation Center, Department of Plastic and Reconstructive Surgery \\ ${ }^{2}$ Taipei City Hospital, Taipei, Taiwan \\ Department of Physical Therapy \\ ${ }^{3}$ National Taiwan University, Taipei, Taiwan \\ School and Graduate Institute of Physical Therapy, College of Medicine
}

\begin{abstract}
Objectives: This case-control study aimed to investigate the predictors of return to work (RTW) following work-related major forearm, wrist or hand injury at the preparation stage of return to work. Material and Methods: A total of 80 clients were recruited and divided into 2 groups depending on their readiness of RTW. The groups were compared with each other with regard to their demographics, compensation status, hand injury severity, health perception, and time off work (TOW) using correlation coefficient. Predictors of RTW were measured by logistic regression analysis. Results: There were no significant differences in demographics and the severity of hand injury between 2 groups. Self-perceived physical functioning $(\mathrm{p}=0.04)$, vitality $(\mathrm{p}=0.01)$, mental health $(\mathrm{p}=0.03)$ and TOW $(\mathrm{p}=0.001)$ were significantly different between Action group and Preparation group. With binary logistic regression analysis, self-perceived vitality (odds ratio $(\mathrm{OR})=1.041)$ and TOW $(\mathrm{OR}=0.996)$ were shown to be strongly predictive of RTW at the preparation stage of return to work. Conclusions: This study has shown that shorter TOW and better self-perceived vitality could predict early readiness for RTW after major work-related forearm, wrist or hand injury.
\end{abstract}

Key words:

Rehabilitation, Vocational, Return to work, Occupational injuries, Hand injuries

\section{INTRODUCTION}

Work-related musculoskeletal disorders have become a major problem in industrialized nations because of their high prevalence [1-3]. However, occupational injury rather than occupational disease accounts for $99 \%$ workrelated injury in Taiwan. Among this, forearm, wrist and hand injuries are the most common anatomical sites for work-related injury and are a major cause of functional impairment. Within the last 3 years the incidence of workrelated injury is 6-6.8 per 1000 persons. Incidentally, compensation claims have, within the last decade, increased from 20000 to 50000 cases annually [4]. Sickness benefit is in excess of 62 million US dollars per annum. Long term sickness absence not only contributes to subsequent loss

This work was financially supported by Bureau of Labor Insurance of Taiwan.

Received: August 10, 2014. Accepted: March 12, 2015.

Corresponding author: Y.-H. Chao, National Taiwan University, School and Graduate Institute of Physical Therapy, College of Medicine, Room 324, 3rd floor, 17 Xuzhou Road, Zhongzheng District, Taipei City 10055, Taiwan (e-mail: yuanhungchao@ntu.edu.tw). 
of earning, productivity, but also increases the need for training replacement workers which increases overall social charges.

Anatomically, hand function relies on extrinsic and intrinsic musculatures originating from forearm and hand. Furthermore, nerve injuries at the forearm or wrist level also seriously impair hand function [5-8]. Hand injury severity has been shown to predict return to work (RTW) [7-10] which is undoubted in minor hand injury group. In clinics, we found out further that some patients following workrelated hand functional impairments could not return to work successfully, especially those with major hand impairment, which might be due to the complete occupational accident labor protection. Instead, we attempt to explore other than medical factors handicapping early RTW in the case of major impairment following work-related forearm, wrist or hand injury.

Readiness for Change Model also known as the Stages of Work Readiness Model, addresses motivational factors that influence behavioral change [3,11,12]. This model arose from the Stage of Change model (SOC) that was applied to the behavioral changes initially in the field of health promotion [13-15] and pain management [16,17]. This model encompasses 5 stages including pre-contemplation, contemplation, preparation, action, and maintenance. Most people would undergo these stages not necessarily in a linear pattern, but e.g., in a spiral pattern. That is, individuals would relapse and cycle through certain stages several times before they reach the maintenance stage $[14,15]$.

The concept of the SOC was generally employed to improve RTW [12,18]. According to Franche [18] and Krause [19], the duration of stages in the Readiness for Return to work is phase specific and determined by the injury or illness. In the acute stage, physical and injury factors are determining predictors of disability, whereas psychosocial factors have stronger predictive value in the subacute and chronic phases of disability $[3,19]$.
Besides, RTW is also a behavior change process operated by the motivation of employee within the social context. The authors of this paper hypothesize that early RTW following work-related forearm, wrist or hand injury is determined by the hand injury severity, and furthermore influenced by psychosocial factors when employees weigh the pros and cons to make decision to return to work.

Self-rated health is thought to be a cognitive process which integrates different information into a concept [20]. It has been proved to be correlated with mortality [21] and depression [22]. Jylhä proposed a model of self-rated health. In this model, individuals have to go through 3 processes before self-rating health [20]. The 1st is based on cultural (e.g., behaviors) and historical (e.g., diagnosis) factors and regards the meaning of health. The 2nd concerns perceived "general health" and is based on expectations. The last concerns what the patients perceive to best explain their condition.

Huisman and Deeg stated that self-rated health should be viewed as a measure of people's perception of their own health rather than their true health, which is a longterm on-going process affected by external and internal states [23]. Global self-perceived health is considered to be associated not only with individual health status but also the social context.

As self-rated health has been identified to predict RTW [11,12,24-27], we proposed that injured workers rated their health before work resumption by the influence of physical function, psychological feeling of role limitation, vitality or social function, as well as several factors around their social environment.

Along these lines, this study aimed to identify the predictors of attempt to change (RTW) from the preparation stage to the action stage following major work-related forearm, wrist or hand injury. Based on Readiness for Return to Work, we included hand injury severity as medical factor, and time off work (TOW), self-perceived health, and demographic data as psychosocial factors 
to be examined and measured. Return to work was defined by the employee's resumption of paid employment.

\section{MATERIAL AND METHODS}

\section{Subjects and procedures}

Recruitment took place from 2 centers between the 21st July, 2009 and 26th January, 2010. Subject inclusion criteria were age 16-60 years and traumatic workrelated forearm, wrist or hand injury graded as major degree by Modified Hand Injury Severity Score (MHISS). All subjects were recommended to return to work by their health care providers. They were requested to answer the following question: "Within 1 week from now are you ready to return to work?" Those who responded "yes" were enrolled into the Action group (action to RTW). Subjects whose answer was "not quite sure" or "no" were enrolled into the vocational rehabilitation programs as Preparation group (preparation for RTW).

A total sample of 80 consecutive subjects was recruited in both groups. Subjects who had additional body trauma, bilateral hand injuries, experienced difficult communicating, or who were self-employed were all excluded from this study. Participants were provided with written (leaflet) and verbal trial information so that informed consent for their involvement could be gained. This study was approved by the Ethics Committee of Chang Gung Medical Foundation, Taiwan.

\section{Modified Hand Injury Severity Score}

Campbell and Kay developed Hand Injury Severity Score (HISS) to classify the severity of hand injury distal to the carpus [28]. The HISS has been found to correlate with the Disability Arm Shoulder and Hand (DASH) questionnaire [10,29], the Purdue Peg Test [30], and the American Medical Association (AMA) test of permanent impairment [31].

The HISS evaluates anatomical components of the hand distal to the carpus in 4 domains known as the ISMN:
Integument (skin and nail), Skeletal (bone and ligament), Motor (tendon) and Neural (nerve and vascular). Every ISMN domain score is totalized and converted into a weighted score that places a pre-defined emphasis of importance on each of the 5 rays of the hand. The end outcome score is inclusive of additional points added for complications associated with compound fractures or contaminated wounds.

Urso-Baiarda et al. created the Modified Hand Injury Severity Score (MHISS) based on the HISS which includes assessment for wrist and forearm [9]. Both HISS and MHISS group hand injury severity into the following 4 categories according to each patient's total point score: Minor $(<20)$, Moderate (21-50), Severe (51-100) and Major (> 100). Modified Hand Injury Severity Score was measured to quantify not only hand injuries, but also wrist and forearm injuries. In this study, every participant's MHISS was calculated from the patient admission notes, operation note, out-patient department records, radiographs and photographs.

\section{Short-Form 36}

Short-Form 36 (SF-36) was used to measure self-perceived health $[26,27]$. This validated tick-box questionnaire contains 8 concepts which are Physical Functioning (PF), Role-Physical (RP), Bodily Pain (BP), General Health (GH), Vitality (VT), Social Functioning (SF), Role-Emotional (RE) and Mental Health (MH). Totally, there are 36 multiple choice questions from which a score between 0-100 is calculated. The higher a score, the better the self-perceived health.

\section{Time off work and demographic data}

In addition to MHISS and self-administered SF-36, we also collected other information such as TOW, demographic data, and compensation status. Time off work was expressed in days from the duration of time between the injury and entry into this study. In Preparation group, 
subjects were making plans to return to work. The duration of time off work was measured from injury to entry into the vocational rehabilitation center. In Action group, they were putting the plans of return to work into action in recent 1 week; time off work was measured from injury to participation in this study.

Demographic data comprise gender, age, marital status, education level; marital status divided into single, married, and others (divorced or widowed). Education level was classified into 3 levels which were $<9$ years (junior high school or below), 9-12 years (senior high school) and $>12$ years (college or above). Compensation status was defined by indicating if total benefits were above, similar to, or less than the previous salary.

\section{Statistical analysis}

Statistical Analysis System (SAS) Enterprise Guide 4.2 (SAS Institute Inc, Cary, NC.) was used in the data analysis with a maximum significance level set at 0.05 . Independent t-tests were used for continuous variables, and $\mathrm{Chi}^{2}$ tests were used to compare categorical variables. In that, $\mathrm{Chi}^{2}$ test was used to analyze the difference in the dependent variables of gender, marital status, educational level and compensation status between Action and Preparation groups, while independent t-tests were applied to test the difference in the dependent variables of MHISS, Time off work and 8 domains such as Physical Functioning (PF), Role-Physical (RP), Bodily Pain (BP), General Health (GH), Vitality (VT), Social Functioning (SF), RoleEmotional (RE) and Mental Health (MH) in the SF-36 between Action and Preparation groups. Pearson correlation coefficient was used to measure the degree of association between variables of time off work.

Binary logistic regression was performed to evaluate the factors related to RTW at the preparation stage following major work-related forearm, wrist or hand injury. In order to analyze the influence of medical and psychosocial factors on the outcome, binary logistic regression analysis was performed using self-perceived health, hand injury severity, TOW, demographic characteristics and compensation status as independent variables, and RTW (Action group) as the outcome variable.

$\mathrm{A} p=0.05$ was considered to be of statistically significant difference. We calculated odds ratios that helped detect the bivariate relationships for RTW at the preparation stage of RTW. The baseline odds are set to be 1.0. An odds ratio $>1.0$ indicates that there is a positive association between the predictive variables of interest to the baseline odds while a value $<1.0$ indicates the inverse. Receiver operating characteristic (ROC) analyses were undertaken to investigate the accuracy of the measurement for predicting a binary outcome. The ROC curve is plotted by using true positive rate (sensitivity) against false positive rate (1-specificity) at various threshold settings. An area under the ROC curve (AUC) and a Hosmer-Lemeshoe Goodness-of-Fit test were used to assess discrimination.

\section{RESULTS}

\section{Study populations}

In total, data of 80 subjects were analyzed. Action group consisted of 8 females and 27 males whose mean age was $35.8 \pm 11.6$ years. In Preparation group, 9 females and 36 males with a mean age of $36.4 \pm 10.2$ years were included. No significant differences in gender, marital status, education level, and compensation status between groups were shown with $\mathrm{Chi}^{2}$ analysis (Table 1). Independent t-tests showed no significant difference in age between groups $(p=0.82)$. Both independent t-tests and $\mathrm{Chi}^{2}$ test showed no significant difference between action and preparation groups in demographics. The average MHISS was 327.6 \pm 262 in Action group, and $330.5 \pm 234.8$ in Preparation group with no signifcant difference found in t-tests ( $\mathrm{p}=0.96)$.

Time off work was 180.2 \pm 126.6 days in Action group, and $279.5 \pm 223$ days in Preparation group which showed 
Table 1. Demographic characteristics of the study group

\begin{tabular}{|c|c|c|c|c|}
\hline \multirow[t]{2}{*}{ Variable } & \multicolumn{3}{|c|}{$\begin{array}{c}\text { Study group } \\
\qquad \begin{array}{c}\mathrm{N}=80) \\
{[\mathrm{n}(\%)]}\end{array}\end{array}$} & \multirow[t]{2}{*}{$\mathrm{p}$} \\
\hline & total & action group & preparation group & \\
\hline Gender & & & & 0.76 \\
\hline male & $63(79)$ & $27(77)$ & $36(80)$ & \\
\hline female & $17(21)$ & $8(23)$ & $9(20)$ & \\
\hline Marital status & & & & 0.68 \\
\hline single & $32(40)$ & $14(40)$ & $1(40)$ & \\
\hline married & $41(51)$ & $19(54)$ & $22(49)$ & \\
\hline other & $7(9)$ & $2(6)$ & $5(11)$ & \\
\hline Education level & & & & 0.23 \\
\hline$<9$ years & $22(27)$ & $13(37)$ & $9(20)$ & \\
\hline $9-12$ years & $43(54)$ & $16(46)$ & $27(60)$ & \\
\hline$>12$ years & $15(19)$ & $6(17)$ & $9(20)$ & \\
\hline Compensation status & & & & 0.69 \\
\hline above & $3(4)$ & $2(6)$ & $1(2)$ & \\
\hline similar & $36(45)$ & $16(46)$ & $20(45)$ & \\
\hline less & $41(51)$ & $17(48)$ & $24(53)$ & \\
\hline
\end{tabular}

significant difference between groups $(p=0.02)$ under independent t-tests. Furthermore, TOW was correlated with MHISS ( $r=0.39, p=0.000)$ and self-perceived PF $(r=-0.37, p=0.000)$. These results indicated that the more defined (higher) was the severity of hand injury, the longer was the absence from work. As our subjects included forearm-, wrist- or hand-injured individuals, a higher MHISS showed more impaired hand function, and a poorer self-perceived physical health was expected.

\section{Health perception}

Mean and standard deviation values for each of the 8 scales of the SF-36 are shown in Table 2. Physical functioning ( $\mathrm{p}=0.04)$, VT $(\mathrm{p}=0.01)$, and $\mathrm{MH}(\mathrm{p}=0.03)$ were shown to differ significantly between Action and Preparation groups when independent t-test was applied.

\section{Predictors of RTW}

From binary logistic regression analysis, 2 out of 16 independent variables were found to be significantly fitting the logistic model. Self-perceived vitality $(\mathrm{B}=0.04, \operatorname{Exp}(\mathrm{B})=1.009$, standard error $(\mathrm{SE})=0.016$, $\mathrm{p}<0.05)$, and TOW (B $=-0.004$, Exp $(\mathrm{B})=0.996$, $\mathrm{SE}=0.002, \mathrm{p}<0.05)$ predicted RTW at the preparation stage following major work-related forearm, wrist or hand injury (Table 3). P of Hosmer and Lemeshoe Goodness-of-Fit test was 0.44. Area under the ROC curve was 0.7238 , indicating moderately accurate prediction of RTW (Figure 1).

\section{DISCUSSION}

This was a preliminary study intended to determine the predictors affecting the behavioral change of return to work from the preparation stage to the action stage 
Table 2. Independent t-tests of 8 items of SF-36 between groups $(\mathrm{N}=80)$

\begin{tabular}{|c|c|c|c|}
\hline \multirow{2}{*}{ Item } & \multicolumn{2}{|c|}{ Score } & \multirow{2}{*}{$\mathrm{p}$} \\
\hline & $\mathrm{M}$ & SD & \\
\hline \multicolumn{4}{|l|}{ Physical functioning } \\
\hline action group & 81.43 & 9.28 & $0.04 *$ \\
\hline preparation group & 75.78 & 14.38 & \\
\hline \multicolumn{4}{|l|}{ Role limitation due to physical problems } \\
\hline action group & 20.00 & 28.31 & 0.93 \\
\hline preparation group & 20.56 & 30.29 & \\
\hline \multicolumn{4}{|l|}{ Bodily pain } \\
\hline action group & 65.03 & 15.18 & 0.14 \\
\hline preparation group & 59.58 & 16.84 & \\
\hline \multicolumn{4}{|l|}{ General health } \\
\hline action group & 66.89 & 17.62 & 0.47 \\
\hline preparation group & 63.73 & 20.52 & \\
\hline \multicolumn{4}{|l|}{ Vitality } \\
\hline action group & 66.86 & 16.43 & $0.01^{*}$ \\
\hline preparation group & 55.78 & 17.48 & \\
\hline \multicolumn{4}{|l|}{ Social functioning } \\
\hline action group & 67.50 & 17.47 & 0.89 \\
\hline preparation group & 66.94 & 19.43 & \\
\hline \multicolumn{4}{|c|}{ Role limitation due to emotional problems } \\
\hline action group & 48.51 & 42.32 & 0.90 \\
\hline preparation group & 47.31 & 39.93 & \\
\hline \multicolumn{4}{|l|}{ Mental health } \\
\hline action group & 69.03 & 13.31 & $0.03^{*}$ \\
\hline preparation group & 61.60 & 16.10 & \\
\hline
\end{tabular}

SF-36 - Short-Form 36; M - mean; SD - standard deviation.

$* \mathrm{p}<0.05$.

Table 3. Odds ratios for binary logistic regression using return to work (RTW) as dependent variable

\begin{tabular}{lccc}
\hline \multicolumn{1}{c}{ Variable } & Wald & OR & $95 \%$ CI \\
\hline Time off work & $5.355^{*}$ & 0.996 & $0.993-0.999$ \\
Vitality & $6.417^{*}$ & 1.041 & $1.009-1.073$ \\
\hline
\end{tabular}

OR - odds ratio; $\mathrm{CI}$ - confidence interval.

$* \mathrm{p}<0.05$. 


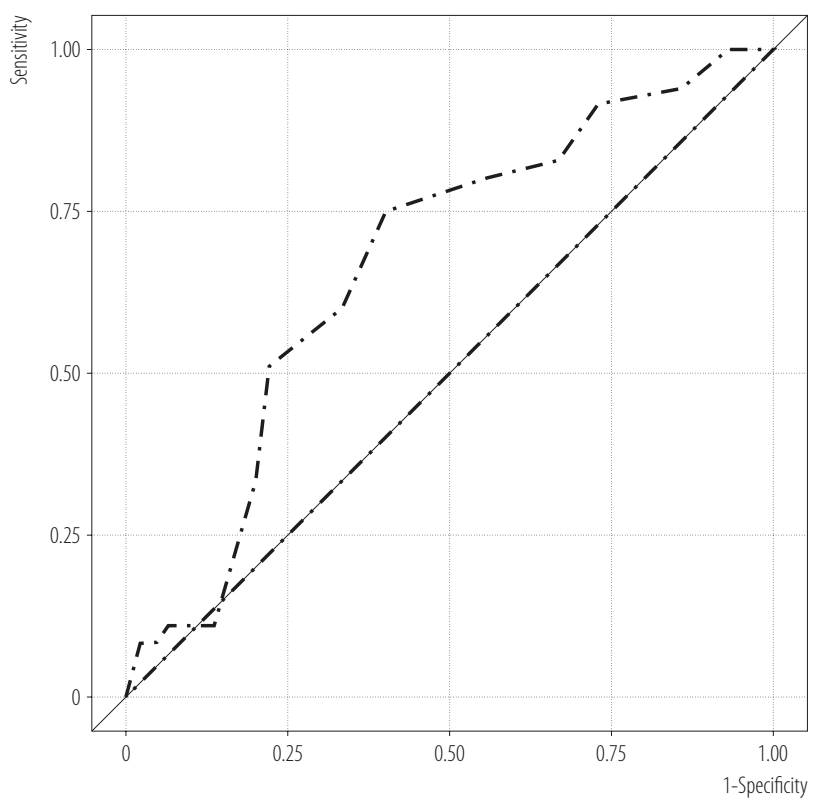

Fig. 1. The receiver operating characteristic (ROC) curve

following work-related major forearm, wrist or hand injury. Binary logistic regression analysis identified that self-perceived vitality and time off work were the factors contributing to predict taking action to RTW at the preparation stage.

In the present study, t-tests showed that time off work was significantly different between preparation and action group, but severity of injury was not. We found that longer sick leave tended to impair return to work, and it was consistent with other results. Atroshi et al. studied long-term sick leave among primary care patients with musculoskeletal disorders, and found that longer sick leave was one of the significant predictors of work disability [27]. To identify predictive factors for work capacity in patients with musculoskeletal disorders, Lydell et al. found that earlier sickness certification periods were predictive of work capacity [32]. Heijbel et al. also found out that shorter duration of sick leave was one of predictors of return to work in chronic musculoskeletal and behavioral disorders [33]. Although Hebert and Ashworth could not identify total days of disability as the predictor of RTW following traumatic work-related lower extremity amputation, days of disability were significantly related to RTW [34].

We did not find a difference in hand injury severity between both groups after data analysis. Nevertheless, TOW was significantly shorter in Action group compared to Preparation group. We have found that early considered RTW was beneficial for labors following workrelated major forearm, wrist or hand injury irrespective of injury severity.

Self-perceived vitality was taken into account in predicting RTW in the present study. It was interesting that labors delayed in planning to return to work following workrelated major forearm, wrist or hand injury perceived poorer vitality rather than physical health. Franche et al. noted that transient depressive symptoms were pervasive in some workers following a workplace injury, and seldom diagnosed as depression, or treated [35]. Jaquet et al. also showed posttraumatic psychological stress as a predictor for work resumption after forearm and wrist nerve injuries [36].

Financial stress was found to affect return to work in several studies [25,34]. In Taiwan, labor insurance systems compensate for 2 years the wage lost as a result of occupational injury causing physician-certified inability to RTW. Workers receive $70 \%$ of insured salary for the 1 st year of sick leave, and the remaining wages are paid by employer. For the 2nd year, the compensation paid by labor insurance will decrease to $50 \%$. In this situation, higher or uninterrupted compensation will sometimes impact early RTW [37,38]. To enhance self-perceived vitality, coping skills training to overcome depression or stress and suitable compensation to release financial pressures need to be implemented in earlier stage of rehabilitation.

Matsuzaki et al. [10] or Lee et al. [30] found hand injury severity might lengthen time to return to work by using Campbell's HISS. Mink van der Molen [31] and this study, using MHISS, also found a similar tendency. A more complicated hand injury sustains a poorer functional 
recovery. Compared with digital nerve injuries, nerve injuries at forearm level were critical to functional outcomes and RTW [6-8]. Jaquet et al. proposed forearm or wrist injury as the leading causes of severe functional disability and prolonged incapacity for work [5].

When hand injury severity was under-controlled, we couldn't find it as one of the factors contributing to predict taking action to RTW at the preparation stage. But, as we studied subjects following work-related forearm, wrist or hand injury, the more severe was the injury, the longer it took to gain functional recovery and be ready to return to work. It was consistent with the study by Matsuzaki et al. [10]. The authors suggested embracing forearm or wrist injury to comprehensively explore the causal relation between the impairment of hand function and RTW, as extrinsic musculatures and motor nerve damages would be involved in this kind of impairment.

Time off work, moreover, correlated with self-perceived physical functioning in this study. Lange et al. found that subjective perception of the accident outcomes as severe was more predictive of developing long-term disability [39]. It means that when someone decides to return to work, her/his perception about the injury severity may affect her/his decision. Lötters et al. also found that perceived physical workload or the perception of the limitation in the ability for return to work was associated with longer sickness absence [24]. Post et al. reported that earlier sickness absence, subjective severity of complaints were predictive of RTW, and physical functioning, physical role problems were important predictors for RTW in musculoskeletal group in contrast to psychological group [26]. Perception is being increasingly considered in RTW outcome studies. Lötters et al.'s results supported different disease-specific risk factors for RTW [24]. Different complaints, such as musculoskeletal vs. psychological or upper limb vs. lower limb lesions might require different approaches. Perceived physical functioning, vitality and mental health were related to RTW following work-related major forearm, wrist or hand injury as data were analyzed. If workers felt poorer vitality which was not fit for their work capacity, they might decide not to change their earlier return-to-work behavior.

Despite the fact that sick leave was correlated with RTW, very few studies on impaired hand function resulting from occupational injury have been carried out so far while studies on RTW following work-related musculoskeletal injury or illness, for example, low back pain, prevailed [12,24,25,40,41].

In the past, several studies reported that major hand functional impairments compared to minor cases took longer to RTW [7-10,28], but on-the-job injuries were not taken into consideration until now. Empirically, we observed that not all labors returned to work following similar injury. Rusch et al. found causal attributions as potential predictors of work-site avoidance after traumatic workrelated hand injuries, and relatively minor injuries were as much at risk for work-site avoidance [42].

Furthermore, financial compensation was found to be associated with an increased risk of a negative vocational rehabilitation outcome [38]. We have been convinced that return to work after work-related injury or illness is a behavior influenced by physical, psychological, and social factors [19].

This study proposed to find out the predictor for early RTW at the preparation stage following work-related major forearm, wrist or hand injury. Our subjects suffered largely from major or severe injury. The process of medical rehabilitation and sick absence was supposed to be longer. The results of present study were consistent with the statement that working disability was phase-specific [3,19]. Physical and injury-related factors are leading factors in the acute phase, whereas psychosocial factors become paramount in subacute or chronic phase.

\section{CONCLUSIONS}

This study identified that prolonged time off work and self-perceived low vitality have negative impact on 
return-to-work following work-related major forearm, wrist or hand injury. Hand injury severity was not identified to predict RTW at the stage of preparation of return to work, but it was correlated with time off work. Aside from the already expected biomedical factors, this study highlights psychological factors as discriminative predictors that should be highly regarded during this preceding phase of RTW. So, we have recommended that rehabilitation experts advise labors suffering from work-related major forearm, wrist or hand injury return to work earlier through holistic vocational evaluations or counseling for job accommodation or avoidance. Besides, vitality interventions to improve physical activity or relaxation is also necessary to improve early return to work.

\section{ACKNOWLEDGMENTS}

The authors sincerely thank the clinical staffs and participants for their contribution to data collection. We also thank the Bureau of Labor Insurance of Taiwan for their financial support of this research.

\section{REFERENCES}

1. Barr AE, Barbe MF, Clark BD. Work-related musculoskeletal disorders of the hand and wrist: Epidemiology, pathophysiology, and sensorimotor changes. J Orthop Sports Phys Ther. 2004;34(10):610-27, http://dx.doi.org/10.2519/ jospt.2004.34.10.610.

2. Schultz IZ, Stowell AW, Feuerstein M, Gatchel R. Models of return to work for musculoskeletal disorders. J Occup Rehabil. 2007;17(2):327-52, http://dx.doi.org/10.1007/s10926-007-9071-6.

3. Schultz IZ, Gatchel RJ. Handbook of complex occupational disability claims: Early risk identification, intervention, and prevention. New York: Springer Science and Business Media; 2005.

4. Bureau of Labor Insurance CLAEY, Taiwan R.O.C. Real occupational benefit payments, by type of benefit 2010 [cited 2010 August 27]. Available from: http://www.bli.gov.tw/ reportY.aspx? $\mathrm{y}=098 \& \mathrm{f}=\mathrm{h} 170$.
5. Jaquet J-B, van der Jagt I, Kuypers PDL, Schreuders TAR, Kalmijn ARS, Hovius SER. Spaghetti wrist trauma: Functional recovery, return to work, and psychological effects. Plast Reconstr Surg. 2005;115(6):1609-17, http://dx.doi. org/10.1097/01.PRS.0000160697.41738.EA.

6. Meiners PM, Coert JH, Robinson PH, Meek MF. Impairment and employment issues after nerve repair in the hand and forearm. Disabil Rehabil. 2005;27(11):617-23, http:// dx.doi.org/10.1080/09638280500030423.

7. Jaquet J-B, Luijsterburg AJM, Kalmijn S, Kuypers PDL, Hofman A, Hovius SER. Median, ulnar, and combined median-ulnar nerve injuries: Functional outcome and return to productivity. J Trauma Inj Infect Crit Care. 2001;51(4):68792, http://dx.doi.org/10.1097/00005373-200110000-00011.

8. Bruyns CNP, Jaquet J-B, Schreuders TAR, Kalmijn S, Kuypers PDL, Hovius SER. Predictors for return to work in patients with median and ulnar nerve injuries. J Hand Surg. 2003;28(1):28-34, http://dx.doi.org/10.1053/jhsu.2003.50026.

9. Urso-Baiarda F, Lyons RA, Laing JH, Brophy S, Wareham K, Camp D. A prospective evaluation of the Modified Hand Injury Severity Score in predicting return to work. Int J Surg. 2008;6(1):45-50, http://dx.doi.org/10.1016/j.ij su.2007.09.001.

10. Matsuzaki H, Narisawa H, Miwa H, Toishi S. Predicting functional recovery and return to work after mutilating hand injuries: Usefulness of Campbell's Hand Injury Severity Score. J Hand Surg [Am]. 2009;34(5):880-5, http:// dx.doi.org/10.1016/j.jhsa.2009.02.009.

11. Chen YH, Lin HT, Lin YT, Chao YH, Lin CH, Wei FC, et al. Self-perceived health and return to work following workrelated hand injury. Occup Med (Lond). 2012;62(4):295-7, http://dx.doi.org/10.1093/occmed/kqr215.

12. Cheng JC-K, Li-Tsang CW-P. A comparison of self-perceived physical and psycho-social worker profiles of people with direct work injury, chronic low back pain, and cumulative trauma. Work. 2005;25(4):315-23.

13. Garber CE, Allsworth JE, Marcus BH, Hesser J, Lapane KL. Correlates of the stages of change for physical 
activity in a population survey. Am J Public Health. 2008; 98(5):897-904, http://dx.doi.org/10.2105/AJPH.2007.123075.

14. Prochaska JO, DiClemente CC, Norcross JC. In search of how people change: Applications to addictive behaviors. Am Psychol. 1992;47(9):1102-14, http://dx.doi.org/10.1037/0003066X.47.9.1102.

15. Chan F, Miller SM, Lee G, Pruett SR, Chou CC. Research. In: Riggar TF, Maki DR, editors. Handbook of rehabilitation counseling. New York: Springer; 2004. p. 159-70.

16. Dijkstra A, Vlaeyen JWS, Rijnen H, Nielson W. Readiness to adopt the self-management approach to cope with chronic pain in fibromyalgic patients. Pain. 2001;90(1-2):37-45, http://dx.doi.org/10.1016/S0304-3959(00)00384-5.

17. Nielson WR, Jensen MP, Kerns RD. Initial development and validation of a multidimensional pain readiness to change questionnaire. J Pain. 2003;4(3):148-58, http://dx. doi.org/10.1054/jpai.2003.436.

18. Franche R-L, Corbière M, Lee H, Breslin FC, Hepburn CG. The readiness for return-to-work (RRTW) scale: Development and validation of a self-report staging scale in lost-time claimants with musculoskeletal disorders. J Occup Rehabil. 2007;17(3):450-72, http://dx.doi.org/10.1007/s10926-0079097-9.

19. Franche R-L, Krause N. Readiness for return to work following injury or illness: Conceptualizing the interpersonal impact of health care, workplace, and insurance factors. J Occup Rehabil. 2002;12(4):233-56, http://dx.doi. org/10.1023/A:1020270407044.

20. Jylha M. What is self-rated health and why does it predict mortality? Towards a unified conceptual model. Soc Sci Med. 2009;69(3):307-16, http://dx.doi.org/10.1016/j.socscimed.2009.05.013.

21. Mackenbach JP, Simon JG, Looman CWN, Joung IMA. Self-assessed health and mortality: Could psychosocial factors explain the association? Int J Epidemiol. 2002;31(6): 1162-8, http://dx.doi.org/10.1093/ije/31.6.1162.

22. Han B, Jylha M. Improvement in depressive symptoms and changes in self-rated health among community-dwelling disabled older adults. Aging Ment Health. 2006;10(6):599605, http://dx.doi.org/10.1080/13607860600641077.

23. Huisman M, Deeg DJ. A commentary on Marja Jylha's "What is self-rated health and why does it predict mortality? Towards a unified conceptual model"(69:3, 2009, 307-16). Soc Sci Med. 2010;70(5):652-4; discussion 655-7, http:/ dx.doi.org/10.1016/j.socscimed.2009.11.003.

24. Lötters F, Burdorf A. Prognostic factors for duration of sickness absence due to musculoskeletal disorders. Clin J Pain. 2006;22(2):212-21, http://dx.doi.org/10.1097/ 01.ajp.0000154047.30155.72.

25. Van der Giezen AM, Bouter LM, Nijhuis FJN. Prediction of return-to-work of low back pain patients sicklisted for 3-4 months. Pain. 2000;87(3):285-94, http://dx.doi. org/10.1016/S0304-3959(00)00292-X.

26. Post M, Krol B, Groothoff JW. Self-rated health as a predictor of return to work among employees on long-term sickness absence. Disabil Rehabil. 2006;28(5):289-97, http:// dx.doi.org/10.1080/09638280500160303.

27. Atroshi I, Andersson IH, Gummesson C, Leden I, Odenbring S, Ornstein E. Primary care patients with musculoskeletal pain: Value of health-status and sense-of-coherence measures in predicting long-term work disability. Scand J Rheumatol. 2002; 31(4):239-44, http://dx.doi.org/10.1080/030097402320318440.

28. Campbell DA, Kay SP. The Hand Injury Severity Scoring System. J Hand Surg. 1996;21(3):295-8, http://dx.doi. org/10.1016/S0266-7681(05)80187-1.

29. Saxena P, Cutler L, Feldberg L. Assessment of the severity of hand injuries using "hand injury severity score", and its correlation with the functional outcome. Injury. 2004;35(5): 511-6, http://dx.doi.org/10.1016/S0020-1383(03)00211-0.

30. Lee C-L, Wu M-Y, Chang J-H, Chiu H-Y, Chiang C-H, Huang M-H, et al. Prediction of hand function after occupational hand injury by evaluation of initial anatomical severity. Disabil Rehabil. 2008;30(11):848-54, http://dx.doi. org/10.1080/09638280701419375.

31. Mink van der Molen AB, Ettema AM, Hovius SER. Outcome of hand trauma: The Hand Injury Severity Scoring 
System (HISS) and subsequent impairment and disability. J Hand Surg [Br]. 2003;28(4):295-9, http://dx.doi. org/10.1016/S0266-7681(03)00082-2.

32. Lydell M, Baigi A, Marklund B, Mansson J. Predictive factors for work capacity in patients with musculoskeletal disorders. J Rehabil Med. 2005;37(5):281-5, http://dx.doi. org/10.1080/16501970510030255.

33. Heijbel B, Josephson M, Jensen I, Stark S, Vingard E. Return to work expectation predicts work in chronic musculoskeletal and behavioral health disorders: Prospective study with clinical implications. J Occup Rehabil. 2006;16(2):17384, http://dx.doi.org/10.1007/s10926-006-9016-5.

34. Hebert JS, Ashworth NL. Predictors of return to work following traumatic work-related lower extremity amputation. Disabil Rehabil. 2006;28(10):613-8, http://dx.doi. org $/ 10.1080 / 09638280500265219$.

35. Franche R-L, Carnide N, Hogg-Johnson S, Côté P, Breslin FC, Bültmann U, et al. Course, diagnosis, and treatment of depressive symptomatology in workers following a workplace injury: A prospective cohort study. Can J Psychiatry. 2009;54(8):534-46.

36. Jaquet J-B, Sandra K, Kuypers PDL, Hofman A, Passchier J, Hovius SER. Early psychological stress after forearm nerve injuries: A predictor for long-term functional outcome and return to productivity. Ann Plast Surg. 2002;49(1):82-90, http://dx.doi.org/10.1097/00000637-200207000-00013.
37. Selander J, Marnetoft SU, Bergroth A, Ekholm J. Return to work following vocational rehabilitation for neck, back and shoulder problems: Risk factors reviewed. Disabil Rehabil. 2002;24(14):704-12, http://dx.doi.org/ 10.1080/09638280210124284.

38. Lysgaard AP, Fonager K, Nielsen CV. Effect of financial compensation on vocational rehabilitation. J Rehabil Med. 2005;37(6):388-91, http://dx.doi.org/10.1080/1650197 0510040948 .

39. Lange C, Burgmer M, Braunheim M, Heuft G. Prospective analysis of factors associated with work reentry in patients with accident-related injuries. J Occup Rehabil. 2007;17(1): 1-10, http://dx.doi.org/10.1007/s10926-006-9039-y.

40. Godges JJ, Anger MA, Zimmerman G, Delitto A. Effects of education on return-to-work status for people with fear-avoidance beliefs and acute low back pain. Phys Ther. 2008;88(2):231-9, http://dx.doi.org/10.2522/ptj.20050121.

41. Storheim K, Ivar Brox J, Holm I, Bø K. Predictors of return to work in patients sick listed for sub-acute low back pain: A 12-month follow-up study. J Rehabil Med. 2005;37(6): 365-71, http://dx.doi.org/10.1080/16501970510040344.

42. Rusch MD, Dzwierzynski WW, Sanger JR, Pruit NT, Siewert AD. Return to work outcomes after work-related hand trauma: The role of causal attributions. J Hand Surg. 2003;28(4):673-7, http://dx.doi.org/10.1016/S0363-50 23(03)00178-3.

This work is available in Open Access model and licensed under a Creative Commons Attribution-NonCommercial 3.0 Poland License - http://creativecommons.org/ licenses/by-nc/3.0/pl/deed.en. 